\title{
A Dual Side Shaping Machine for Industrial Applications
}

\author{
Dr. M. K. Marichelvam ${ }^{1}$, Mr. K.Kandakodeeswaran ${ }^{2}$ \\ ${ }^{1,2}$ Department of Mechanical Engineering, Mepco Schlenk Engineering College, \\ Sivakasi, Tamilnadu, India
}

*Corresponding Author: Dr. M. K. Marichelvam, Department of Mechanical Engineering, Mepco Schlenk Engineering College, Sivakasi, Tamilnadu, India

\begin{abstract}
Most of the industries are having a various types of reciprocating machines for performing machine operation on small size of work. Usually shaper, broaching machine and planner are used for machining a small area of work with less quantity. These machines are used for machining very small area of plain surface, vertical surface, angular surface, grooving etc. It removes the materials from job only at forward stroke. So it takes more machining time to complete the product. In order to overcome this problem, a small dual shaper machine is developed for machining two work pieces at a same time. In this machine, it has both the direction of ram movement and it removes a material from two work pieces simultaneously. So, the machining time will be reduced and the production rate will be increased.
\end{abstract}

Keywords: shaper, dual side shaper, machining Centre

\section{INTRODUCTION}

In general, the shaper can produce any surface composed of straight line elements. Modern shapers can generate contoured surface. The main purpose of shaping machine is to machine plain horizontal surface. It is possible to from vertical and angular surfaces also. With proper tools and accessories even irregular surfaces can be formed. As per the of motion of the shaper they are

- Crank type

- Geared type

- Hydraulic type

By moving the work piece across the path of the reciprocating tool a flat surfaces is generated regardless of the shape of the tool. With the special tools, attachments and devices for holding the work, a shaper can also be used to cut external and internal keyways, gears, racks, dovetails, T-slots and other miscellaneous shapes. Shaping is essentially an inefficient method of metal removal but the simplicity of the process coupled with short set up time and cheap tooling makes it extremely useful for the single job.

The most common type of horizontal shapers is the production push cut shaper. This type of shaper consists of a frame or column supported on a base, a reciprocating ram and work table. The frame houses the drive mechanism of the shaper. The tool slide swivel base is held on the circular seat on the ram and is graduated to indicate the angle of swivel. The apron consisting of the clapper box the clapper block and the tool post is clamped on the vertical slide by a screw. It can be swiveled about the apron swivel in by releasing the clamping screw. The clapper blocks which carries the tool post is connected to the clapper box means of a hinged pin. The researchers suggested that a shaping machine for dividing a deformable mass, such as a meat product, into separately shaped portions comprises a stock container, at least two piston-cylinder units for alternately feeding in the mass from the stock container to a shaping plate provided with shaped recesses, and also means for removing the shaped portions from the shaping plate [1].

Some authors suggested that twin mounted double sided reciprocating shaping mechanism is provided which is formed in the shape of an acute isosceles triangle whereby the bottom is opened to the ground and each cutting mechanism is bent or deformed along the longitudinal axis to form to a 
conical shape when rotated about the center axis of the isosceles triangle. The twin mounted double sided reciprocating shaping mechanism is adapted to be used for cutting and shaping and forming trees, bushes and the like in the contour of a cone [2].

The invention relates to a machine for cutting down and shaping trees, designed to cut down, strip and truncate trees, consisting of a support and cutting down-stripping-truncating equipment likely to be adapted to a self-propelling device, said equipment carrying a movable framework on which the cutting-truncating and stripping elements are positioned, a machine wherein the components there of are substantially secured along a one and same axis, the stripping element carrying at least two blades is explained in [3].This invention relates to improvements in machines for building pneumatic tires [4]. It includes features which are beneficial in the building of almost any standard type of pneumatic tire, although it is most particularly suited to the fabrication of radial ply tires. In the manufacture of radial ply tires, comprised of single or multiple plies composed of wire and/or textile, it is conventional practice to wind the rubberized ply or plies on a revolving cylindrical tire building drum with the wires or cords forming high angles.

Some authors suggested that multi-touch capacitive touch sensor panel can be created using a substrate with column and row traces formed on either side of the substrate. To shield the column (sense) traces from the effects of capacitive coupling from a modulated Vcom layer in an adjacent liquid crystal display (LCD) or any source of capacitive coupling, the row traces can be widened to shield the column traces, and the row traces can be placed closer to the LCD [5].Tire shaping machine invention relates to improvements in machines for building pneumatic tires [6]. It includes features which are beneficial in the building of almost any standard type of pneumatic tire, although it is most particularly suited to the fabrication of radial ply tires.

In the manufacture of radial ply tires, comprised of single or multiple plies composed of wire and/or textile, it is conventional practice to wind the rubberized ply or plies on a revolving cylindrical tire building drum with the wires or cords forming high angles (in the neighborhood of 90) to a plane that is perpendicular to the finished tire axis. The opposite ends of the ply or plies are each then folded around a rubberized bead wire, and sidewall and under breaker stock are added. The semi-completed carcass is then removed from the tire building drum and placed on a shaping machine (or, alternatively, the carcass may have originally been built on a shaping machine drum), wherein a low angle wire breaker strip (or circumferential restraining ply) and a tread slab are added thereto, and the tire is brought to its ultimate shape is explained in [7]. The application of the breaker strip or strips to the semi-completed tire carcass is a critical step in the fabrication of a tire. It requires that the circumference of the tire carcass be extended to the precise diameter at which this component is to be added is explained in [8]. Normally in the manufacturing industry the shaping machine is used to manufacture a component, the time consumption is more, if single tool is used to manufacture the component. In order to reduce the time taken to produce a component, a new type of shaper machine was developed. In this new type of machine two shaping tools are used. Therefore two work pieces can be machined at the same time. In dual side shaper machine the machining time will be less when to normal shaper. The power consumption is same in both the shaper machine, and the speed of the ram will be controlled.

\section{Design Calculations of The COMPONENTS}

The components used in the dual side shaper machine are

- Frame

- Pulley

- Single Phase Induction Motor

- V-Belt

- Shaft

- Roller Bearing

- Shaping Tool

\subsection{V -Belt Design Calculation}

Large pulley diameter

$$
=30 \mathrm{~cm}=300 \mathrm{~mm}
$$


Small pulley diameter

Belt width

Power

Speed of motor

Rated power

$$
\begin{aligned}
& =4 \mathrm{~cm}=40 \mathrm{~mm} \\
& =38.5 \mathrm{~cm}=385 \mathrm{~mm} \\
& =100 \mathrm{~W} \\
& =1300 \mathrm{rpm} \\
& =150 \mathrm{~T}
\end{aligned}
$$

2.1.1. Selection of the V Belt

From PSG data book for 100W, A section belt is chosen.

2.1.2. Selection of Pulley Diameter

$\mathrm{I}=\mathrm{D} / \mathrm{d}=\mathrm{N} / \mathrm{n}$

$7.5=\mathrm{N} / \mathrm{n} \quad \mathrm{n}=1300 / 7.5=173.33$

Recommended minimum diameter $\mathrm{d}=75 \mathrm{~mm}$

$\mathrm{I}=300 / 40=7.5 \mathrm{~mm}$

Recommended C/D ratio $=0.85$

2.1.3. Calculation Pitch Length

From PSG data book page no 7.61

$\mathrm{L}=2 \mathrm{c}+\pi / 2(\mathrm{D}+\mathrm{d})+\frac{(D-d)}{4 C}$

$\mathrm{C}=385 \mathrm{~mm}$

$C / D=0.85$

$\mathrm{C}=0.85 * 300=255 \mathrm{~mm}$

$\mathrm{C}=255 \mathrm{~mm}$

$\mathrm{L}=2 * 385+\pi / 2(300+40)+\frac{(300-40)}{4 * 385}$

$\mathrm{L}=1347.96 \mathrm{~mm}$

Standard length $\mathrm{L}=2703 \mathrm{~mm}$

2.1.4. Calculation of Maximum Power Capacity

$\mathrm{A} \mathrm{KW}=\left(0.45 \mathrm{~S}^{-0.09}-\frac{19.6^{2}}{d e}-0.765^{*} 10^{-4} s^{2}\right) \mathrm{s}^{*} 125$

$V=\frac{\pi D N}{60}$

$V=\frac{\pi * 40 * 1300}{60}=2.72 \mathrm{~m} / \mathrm{s}$

$\mathrm{A} \mathrm{KW}=\left(0.45(2.72)^{-0.09}-\frac{19.6^{2}}{85.5}-0.765^{*} 10^{-4}(2.72)^{2}\right) 2.72 * 125$

A KW=0.49KW

2.1.5. Calculation of Arc of Contact

$\alpha=180-\left(\frac{D-d}{c}\right) * 60$

$\alpha=180-\left(\frac{300-40}{385}\right) * 60$

$=139.48$ degree

Correction factor $\mathrm{F}_{\mathrm{d}}=0.89$

Normal torque at $16 \mathrm{hrs}$

$\mathrm{F}_{\mathrm{a}}=1.3$

$\mathrm{F}_{\mathrm{c}}=0.94$

2.1.6. Calculation of Number of Belt

Number of belt $=\frac{P * F a}{k w * F c * F d}$ 
$=\frac{100 * 1.3}{0.49 * 10^{3} * 0.94 * 0.89}$

$=0.3 \cong 1$

Number of belt $\quad=1$ belt

2.1.7. Calculation of Actual Length

Standard Length $(\mathrm{L})=2703 \mathrm{~mm}$

$\mathrm{A}=\frac{L}{4}-\pi\left(\frac{\mathrm{D}+\mathrm{d}}{8}\right)$

$=\frac{2703}{4}-\pi\left(\frac{300+40}{8}\right)$

$\mathrm{A}=542.25 \mathrm{~mm}$

$\mathrm{B}=\frac{(D-d)^{2}}{8}=\frac{(300-40)^{2}}{8}$

$=8450 \mathrm{~mm}$

$\mathrm{C}=\mathrm{A}+\sqrt{\mathrm{A}^{2}-\mathrm{B}}$

$=542.25+\sqrt{542.25^{2}-8450}$

$\mathrm{C}=1076.90 \mathrm{~mm}$

\section{Modeling of MaChine And Machine Components}

The 3-D modeling of machine and the components is carried out in Solid Works software. The modeling application also provides "features based" solid bodies by directing editing capabilities, which allow changing and updating solid bodies by directing editing the dimensions of a solid feature or by other geometric construction techniques.

\subsection{Parts to be Designed}

The various parts to be designed in solid works software are

- Shaft

- Pulley

- Work table

- Angle

- $\operatorname{Ram}$

- Work piece

\subsection{Isometric View of Dual Shaper}

The isometric view of dual shaper machine is illustrated in Figure 1

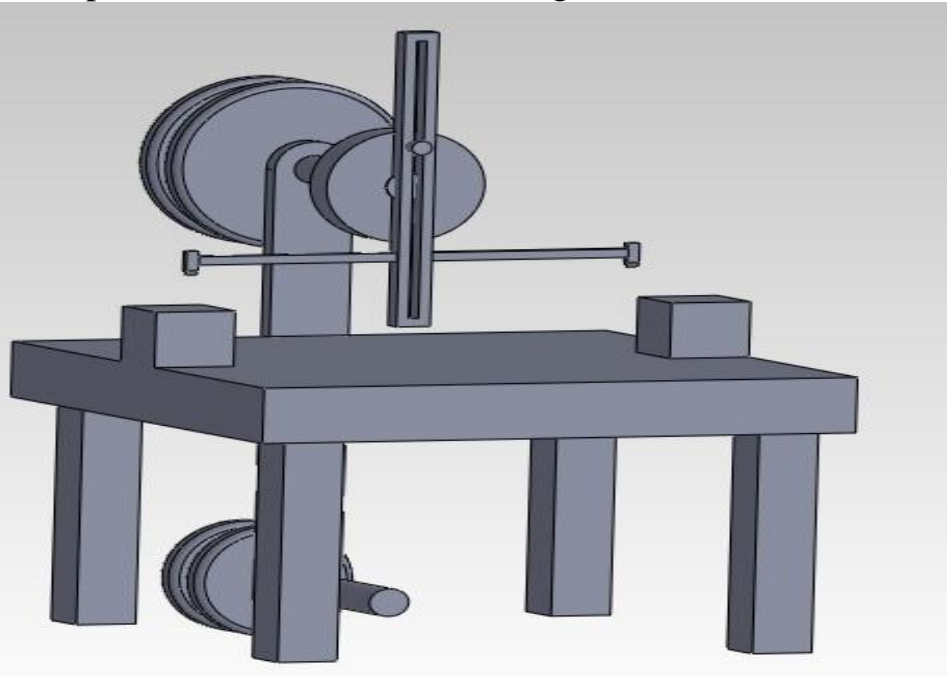

Figure1. Isometric View of Dual Shaper 


\subsection{Pulley}

The modelling of pulley is depicted in Figure 2. The pulley material used here is cast iron.

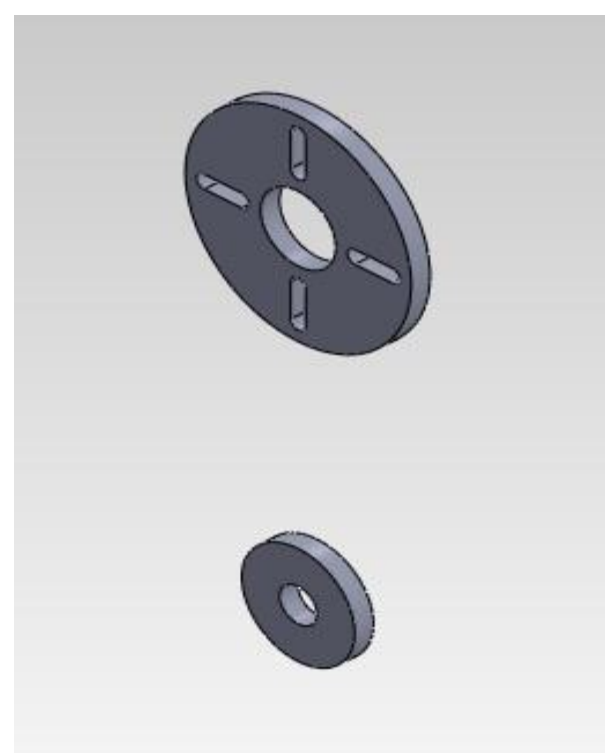

Figure2. Isometric View of Pulley

\subsection{Table}

The isometric view of table is depicted in Figure 3.

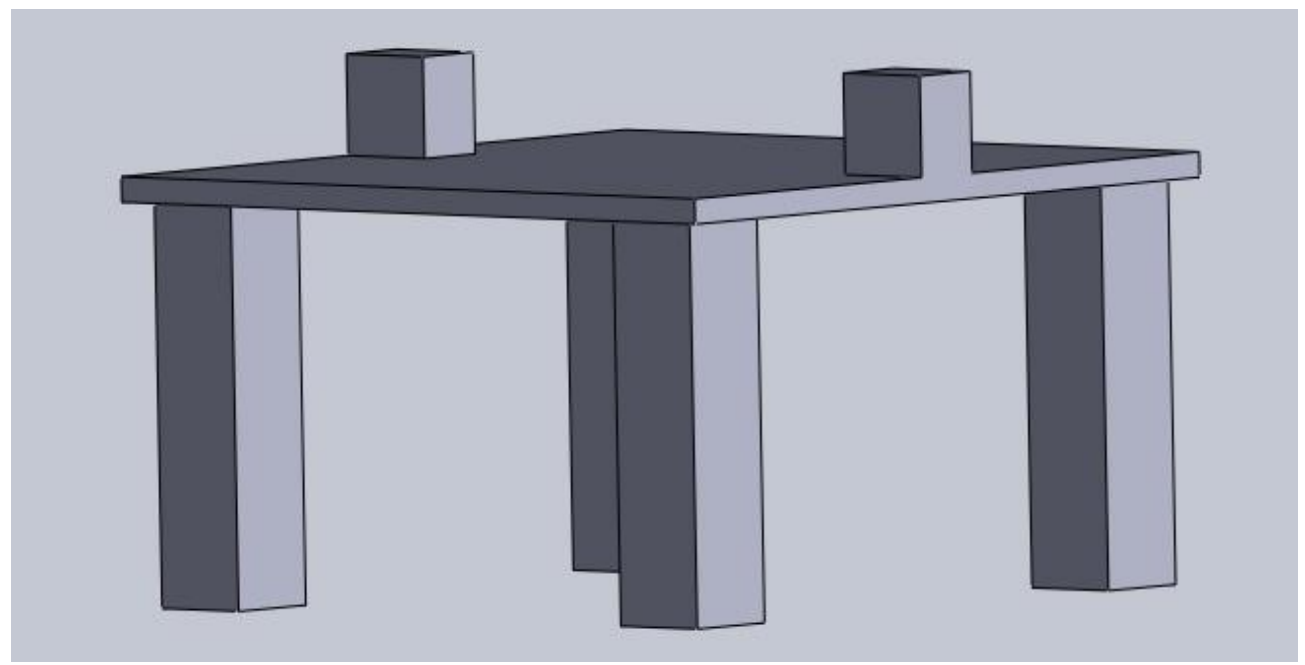

Figure3. Isometric View of Table

\subsection{Shaft}

The isometric view of shaft is shown in Figure 4.

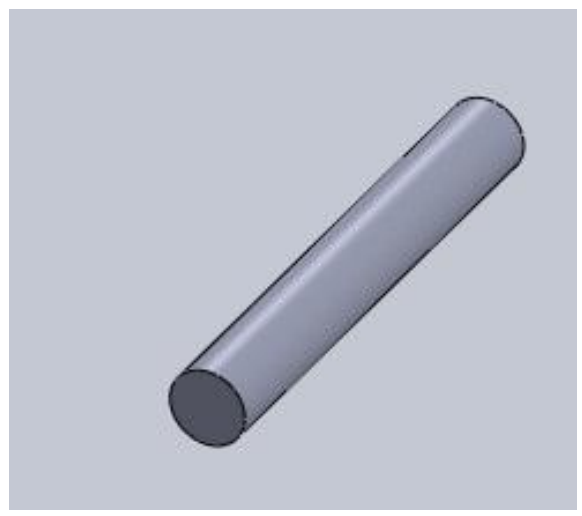

Figure4. Isometric View of Shaft 


\subsection{Wheel}

The isometric view of wheel is shown in Figure 5.

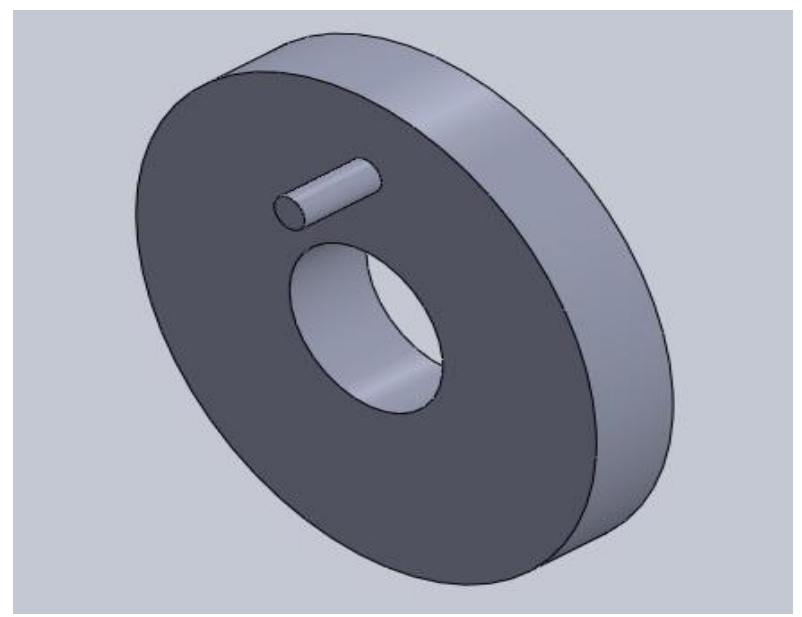

Figure5. Isometric View of Wheel

\subsection{Ram}

The isometric view of ram is depicted in Figure 6.

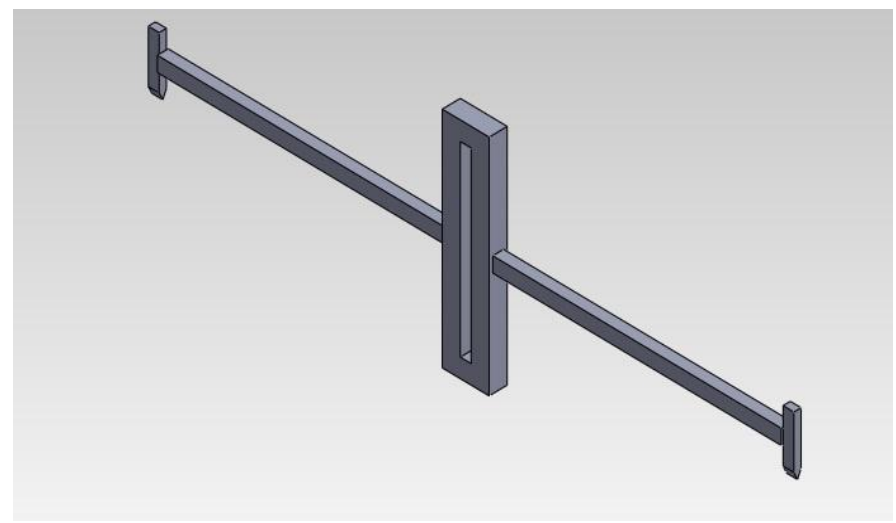

Figure6. Isometric View of Ram

\section{LAyout OF THE MACHINE AND MechaniSMS USED}

The components (or) parts are assembled and the machining process is carried out. The fabrication of dual side shaper machine is clearly shown in figure 7.

\section{FABRICATION OF DUAL SIDE SHAPER MACHINE}

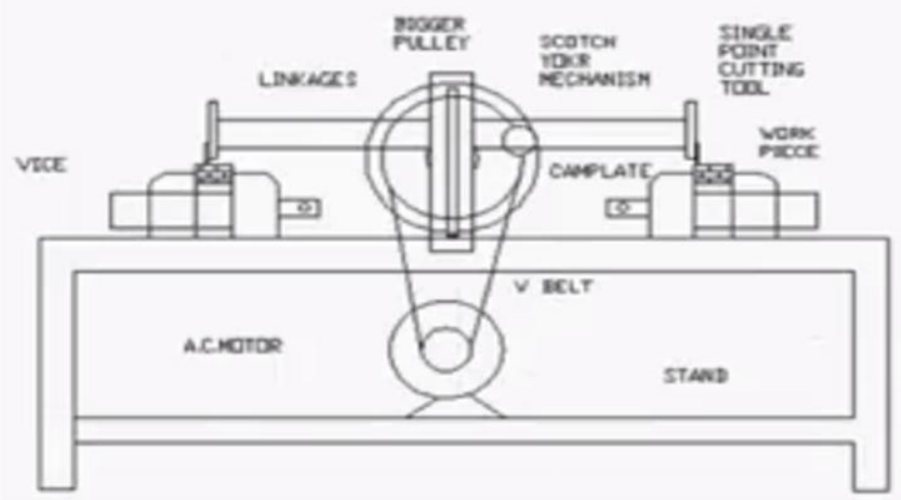

Figure7. Layout of the dual side shaper machine 


\subsection{Mechanisms Used in Dual Shaper}

The mechanism used in the dual shaper is explained below.

\subsubsection{Scotch Yoke Mechanism}

The Scotch yoke (also known as slotted link mechanism) is a reciprocating motion mechanism, converting the linear motion of a slider into rotational motion or vice versa. The piston or other reciprocating part is directly coupled to a sliding yoke with a slot that engages a pin on the rotating part. The location of the piston versus time is a sine wave of constant amplitude, and constant frequency given a constant rotational speed. This mechanism is generally found on shaping machines where single point cutting tool is mounted on the front of the slider or ram, in a hinged tool post. The tool cuts on the slow forward stroke and lifts over the work piece on the quick return stroke. The slotted link rocks from side to side, driven by the sliding block on the bull wheel. The various views of the proposed dual shaper machine is shown in below figures 8-10.

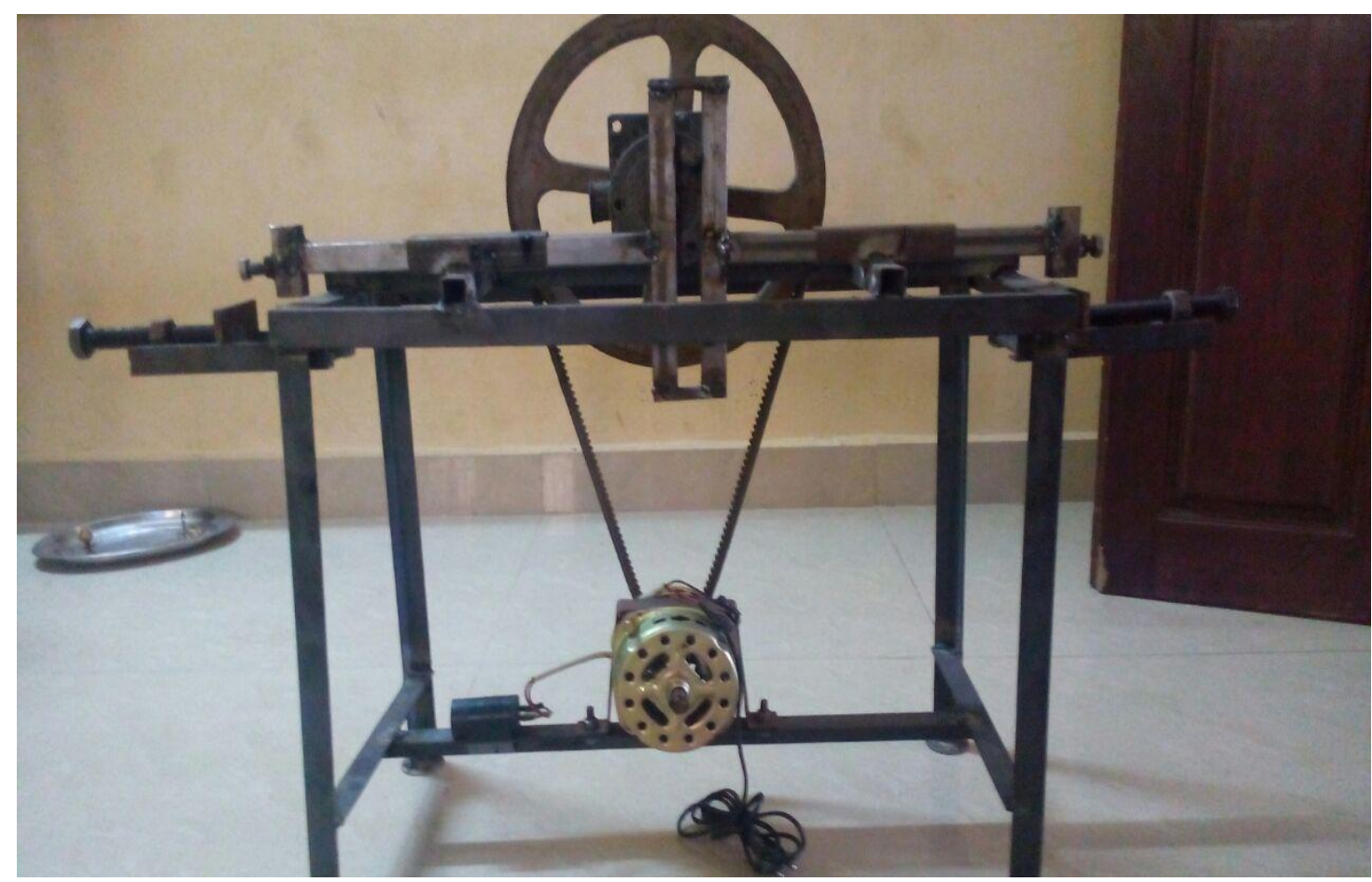

Figure8. Front View of Dual Shaper

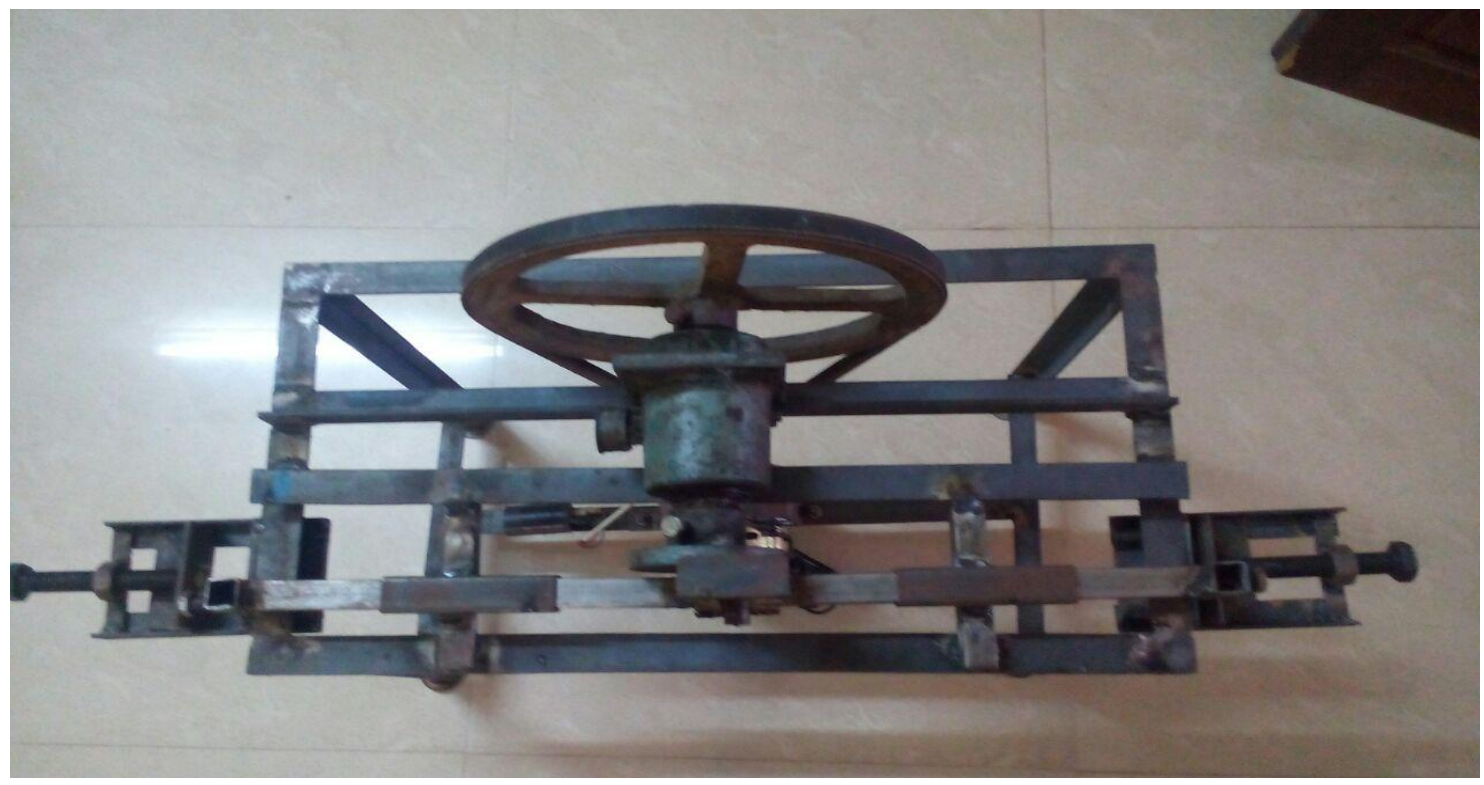

Figure9. Top View of Dual Shaper 


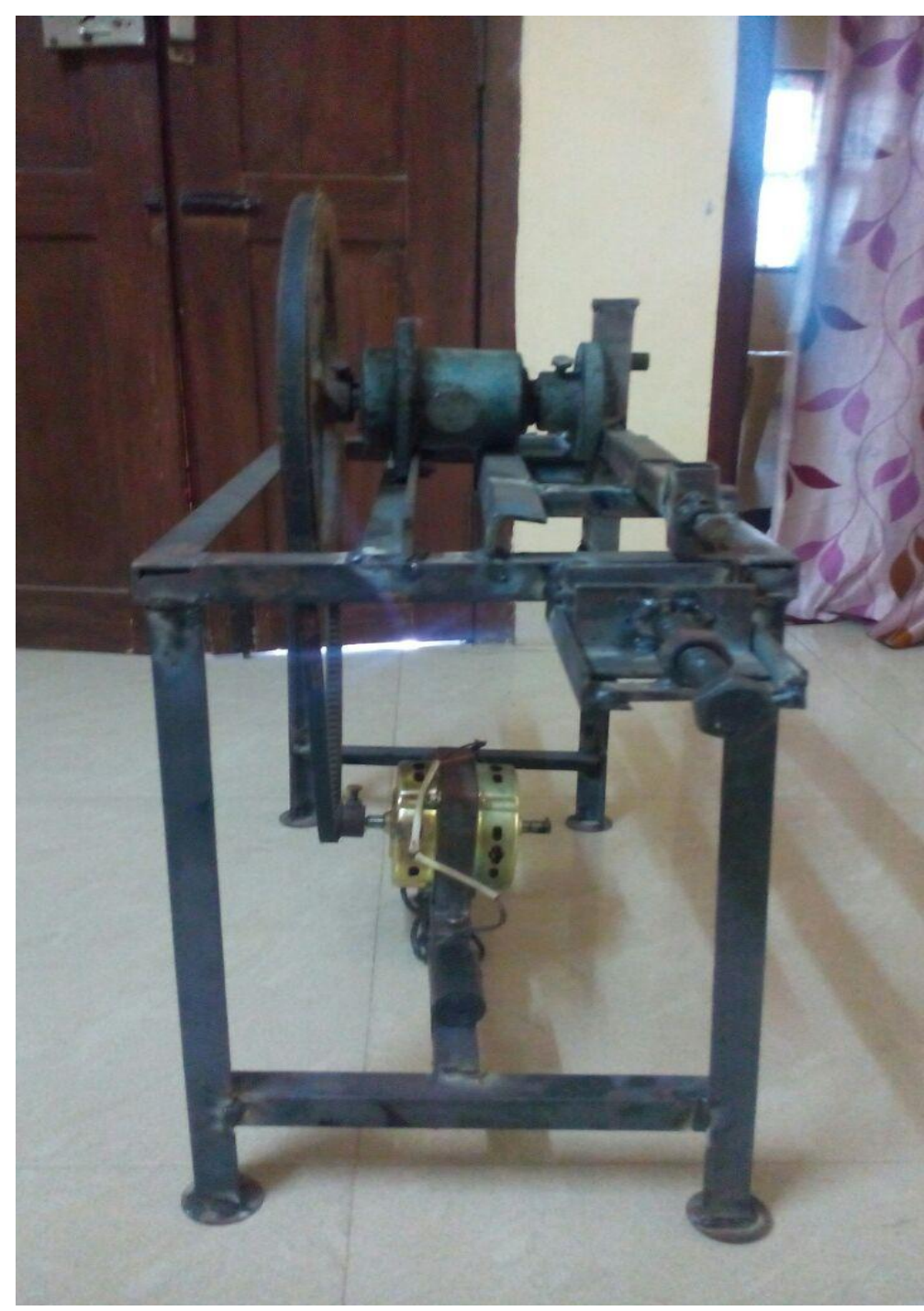

Figure10. Side View of Dual Shaper

\subsection{Machining Time Calculation}

Length of the cutting stroke

Time required by cutting stroke

Cutting speed

Plate size

Total length of stroke

Cutting time for single work piece

This dual shaper return time

Total time

$$
\begin{aligned}
& =50 \mathrm{~mm} \\
& =2 \mathrm{sec} \\
& =25 \mathrm{~mm} / \mathrm{sec} \\
& =20 * 20 * 20 \\
& =20+20 \\
& =40 \mathrm{~mm} \\
& =40 / 25 \\
& =1.6 \mathrm{sec} \\
& =1.6 / 2 \\
& =0.8 \mathrm{sec} \\
& =2.4 \mathrm{sec}
\end{aligned}
$$

Total number of stroke necessary to complete the cut $=40 / 2$

$$
=20 \mathrm{~mm}
$$

Total time required to complete the cut $=2.4 * 20 / 60$

$$
=0.8 \mathrm{~min}
$$




\section{CONCLUSIONS AND FUTURE RESEARCH}

In this paper, a dual side shaper is designed and fabricated. This dual side shaper machine is used to manufacture components similar to a standard shaper machine. However, the machining time required for this dual shaper is less as compared to the normal shaper. Hence, the production rate is increased in the dual side shaper machine when compared to the normal shaper. The designed dual shaper has been used for only trial production. In the future it would be used for commercial production in industries.

\section{REFERENCES}

[1] Hnatovsky, C., Shvedov, V. G., Shostka, N., Rode, A. V., \& Krolikowski, W. (2012). Polarizationdependent ablation of silicon using tightly focused femtosecond laser vortex pulses. Optics Letters, 37(2), 226-228.

[2] D.M. Karnakis, J. Fieret, P.T. Rumsby, M.C. Gower, shaping using reshaped pulsed Gaussian laser beams, in: Proceedings of SPIE, vol. 4443, 2001.

[3] "Cigar bunch shaper mechanism." U.S. Patent 2,102,298, issued December 14, 1937.

[4] Safdar, S., Li, L., Sheikh, M. A., \& Liu, Z. (2007). Finite element simulation of laser tube bending: Effect of scanning schemes on bending angle, distortions and stress distribution. Optics \& Laser Technology, 39(6), 1101-1110.

[5] SP Hotelling, BR Land (2011) 'DUAL SHAPER'- US patent7,920,129.

[6] KR Lessard, JM McElrathJr (1983) 'DOUBLE SIDE RECIPROCATING SHAPER'-US Patent 4,383,401.

[7] T.V. Sundararajamoorthy and N. Shanmugam (1982) 'MACHINE DESIGN', Anuratha Publications, Chennai, India.

[8] Khurmi,R.S and Gupta, J.K.(1997) 'A TEXTBOOK OF MACHINE DESIGN', S. Chand Publications, New Delhi, India.

\section{AUTHORS' BIOGRAPHY}

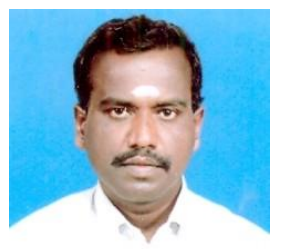

M. K. Marichelvam, received his B.E. degree in Mechanical Engineering from Madurai Kamaraj University, Madurai, India, in 2000. He has obtained a Masters in Engineering in Industrial Engineering from Madurai Kamaraj University, Madurai, India, in 2002. He has obtained Ph.D. in Mechanical Engineering from Anna University, Chennai, India in 2015. He is currently working as Assistant Professor (Sr. Grade) in Mechanical Engineering Department, Mepco Schlenk Engineering College, Sivakasi, India. His active areas of interests are Manufacturing Scheduling, Multi-objective optimization, Industrial and Production Management and optimization techniques. He has published many research papers in the Journals of International repute. He has presented papers at several international conferences.

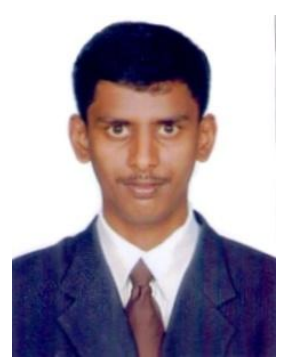

K. Kandakodeeswaran, received his B.E. degree in Mechanical Engineering from Anna University, Chennai, India, in 2012. He obtained Master degree in Computer Integrated Manufacturing from Anna University, Chennai, India, in 2014. He is currently working as an Assistant Professor in Mechanical Engineering Department, Mepco Schlenk Engineering College, Sivakasi, India. His areas of interests are Design and Manufacturing. He has published a research papers in the Journals of International repute. He has presented papers at some national conferences.

Citation: Dr. M. K. Marichelvam \& Mr. K. Kandakodeeswaran (2017). A Dual Side Shaping Machine for Industrial Applications, International Journal of Modern Studies in Mechanical Engineering (IJMSME), 3(3), pp.40-48, DOI: http://dx.doi.org/10.20431/2454-9711.0303005.

Copyright: () 2017 Dr. M. K. Marichelvam \& Mr. K. Kandakodeeswaran This is an open-access article distributed under the terms of the Creative Commons Attribution License, which permits unrestricted use, distribution, and reproduction in any medium, provided the original author and source are credited 